\section{A promoção da saúde e a prevenção integrada dos fatores de risco para doenças cardiovasculares: até quando ficaremos "enxugando o gelo"?}

The Promotion of Health and the Integrated Prevention of Risk Factors for Cardiovascular Diseases: until when we will be "mopping up the ice"?

\section{Márcia Guimarães de Mello Alves ${ }^{2}$}

Em primeiro lugar, gostaria de agradecer a oportunidade de participar deste debate dada a relevância do tema - as doenças cardiovasculares - que continua a nos desafiar com suas elevadas taxas de morbi-mortalidade e as consequências daí advindas para os indivíduos e para a sociedade, a despeito de todo avanço tecnológico no tocante ao seu diagnóstico, tratamento e reabilitação.

No texto apresentado, as autoras abordam a importância das ações de "base comunitária" no enfrentamento desses agravos que são, há muito tempo (e não apenas atualmente), de elevada prevalência no país e no mundo. Certamente, a mudança no perfil demográfico das populações contribui para esse aumento, mas o fato é que se trata de problemas de saúde cada vez mais precoces na vida humana.

Por meio de uma revisão narrativa, identificam as principais experiências no âmbito internacional e nacional, "no combate às doenças cardiovasculares através de ações de promoção da saúde e prevenção integrada dos principais fatores de risco". Além disso, se propõem a refletir sobre os desafios da Estratégia de Saúde da Família para enfrentamento dessa questão, uma vez que identificam a potencialidade dessa estratégia na forma de atuar em saúde para a transformação do "modelo de assistência tradicional" em outro com ênfase nas ações de promoção da saú- de e de prevenção de doenças, além da perspectiva de atuar de forma mais interativa com o território e seus atores. Em tese, a estratégia possui maior possibilidade de atingir alguns dos objetivos almejados pelos normativos da saúde, a partir do texto constitucional de 1988: integralidade das ações, acesso universal aos serviços, hierarquização da assistência e participação popular. Da mesma forma, procuram refletir sobre os limites encontrados, a partir de experiências analisadas por outros autores, sobre a obtenção de resultados efetivos das ações de saúde no âmbito local, no sentido de diminuir a morbi-mortalidade pelas doenças cardiovasculares.

Vale destacar, para fim deste debate, dois aspectos que chamam a atenção no texto e no âmbito da Saúde Pública em geral: a ideia de que a promoção de saúde, tal como vem sendo formulada, dará conta de resolver esses problemas sanitários permanentes - ainda que os resultados das intervenções não apontem na direção de sua redução efetiva - e a ideia de que a abordagem a partir da comunidade tem maior chance de ser efetiva.

Ainda que não fique clara qual a posição defendida pelas autoras sobre esses aspectos, chama-nos a atenção a ausência de uma análise mais detalhada acerca do limitado alcance das experiências analisadas, ainda que destaquem autores que apontam para a importância de "um ambiente político favorável, o empenho dos gestores locais, a presença de redes sociais atuantes no território e as ações intersetoriais" como "peçaschave" desse processo. Em geral, as experiências analisadas detêm-se na avaliação de intervenções voltadas à mudança do estilo de vida dos indivíduos, ainda que os resultados das intervenções feitas permaneçam reduzidos, o que nos leva a questionar a efetividade das mesmas.

As intervenções, no âmbito internacional e no Brasil (principalmente na Estratégia de Saúde da Família), em que pese a constatação no texto das autoras da "associação de fatores complexos e multivariáveis” na determinação das doenças crônicas não transmissíveis, incluindo as cardiovasculares, preocupam-se em mapear fatores de risco ambientais de natureza comportamental, como "hábitos alimentares inadequados, o sedentarismo e a obesidade, associados às mudanças no estilo de vida como a cessação do tabagis-

\footnotetext{
${ }^{2}$ Universidade Federal Fluminense; marciagmalves@gmail.com
} 
mo e o controle do estresse psicoemocional (grifo meu)". Muito tem sido produzido no Brasil, e fora dele, sobre outros determinantes das doenças cardiovasculares, como os determinantes sociais ${ }^{1}$, como o meio-ambiente, as desigualdades sociais, o efeito do trabalho na vida humana ${ }^{2}$ e as relações sociais mais imediatas ${ }^{3}$. Então, sempre surpreende que, a despeito de se reconhecer que "o padrão comportamental e os hábitos de vida estão estreitamente relacionados com as condições objetivas de oferta, demanda, consumo, modismo e ainda representações sociais, da cultura e das relações sociais estabelecidas na sociedade", nós, pesquisadores, técnicos ou profissionais de saúde, continuemos a "enxugar o gelo".

Não se trata, certamente, de abandonar uma prática em detrimento de outra, mas de buscar alternativas que agreguem essas outras variáveis na rede de determinação dessas doenças e, por conseguinte, nas medidas que visem o seu enfrentamento.

Caso contrário, continuaremos a responsabilizar os indivíduos pelas elevadas prevalências das doenças cardiovasculares "como algo ligado à esfera privada, da responsabilidade dos indivíduos, colocada em termos de escolhas comportamentais" 4 , simplesmente porque não "sabemos" (dado que implicaria em mudanças estruturais na organização social, fora de nosso alcance individual) como dar conta desses outros fatores. O que percebemos no cotidiano das pessoas, nos serviços de saúde, ou fora desses, é que os indivíduos que vivenciam essas doenças bem como seus familiares atribuem as causas de seu adoecimento a outros fatores, distintos daqueles relacionados ao "estilo de vida", apesar da "grande verdade" dos números dos estudos epidemiológicos centrados nesses últimos. Mais uma vez afirmo que não se trata de abrir mão dos achados desses estudos, mas mudar o foco, agregar outros fatores, inclusive estudos qualitativos que buscam a referência das "pessoas comuns"3,5. Ao contrário da sensação de empoderamento "preconizada” pelas políticas de promoção à saúde, é cada vez maior o sentimento de impotência dos indivíduos, sejam os usuários dos serviços de saúde, seus familiares ou os profissionais de saúde, especialmente os da estratégia de saúde da família, com contato mais próximo do cotidiano da vida dessas pessoas.

Outro aspecto a ressaltar é a ideia de que as ações podem ser efetivas, se abordadas no âmbito da comunidade, conceito-chave na promoção da saúde ${ }^{5}$. Não cabe aqui realizar uma abordagem sobre esse tema, mas considero importante nos referenciarmos mais uma vez ao artigo de Castiel $^{4}$ sobre a generalização do conceito e a precariedade de sua leitura sobre o que seja comunidade nos últimos tempos, marcados por profunda individualização.

No nosso ponto de vista, a efetividade das ações de saúde depende da superação da promoção da "saúde das populações em países periféricos com focalização de políticas para segmentos mais pobres e excluídos” e também a superação "do autoritarismo típico da cultura da saúde pública vigente" ${ }^{5}$. Sem mudanças profundas na estrutura social e econômica creio que fica difícil!

\section{Referências}

1. Cesse EAP. Epidemiologia e determinantes sociais das doenças crônicas não transmissíveis no Brasil [tese]. Recife (PE): Fundação Oswaldo Cruz (Fiocruz); 2007.

2. Alves MGM. Pressão no trabalho: estresse no trabalho e hipertensão arterial em mulheres no Estudo Pró-Saúde [tese]. Rio de Janeiro (RJ): Fundação Oswaldo Cruz (Fiocruz); 2004.

3. Alves MGM. A Voz do Hipertenso: Representações sociais da Hipertensão Arterial - Um Estudo de Caso em Jurujuba, Niterói, RJ. [dissertação]. Rio de Janeiro (RJ): Fundação Oswaldo Cruz; 1998.

4. Castiel LD. Promoção de saúde e a sensibilidade epistemológica da categoria "comunidade". Rev Saude Publica 2004; 38(5):615-22.

5. Stotz EM, Araujo JWG. Promoção da saúde e cultura política: a reconstrução do consenso. Saude soc. $2004 ; 13(2): 5-19$. 


\section{Os autores respondem}

\section{The authors reply}

Dois pontos nos chamam atenção na valiosa contribuição da professora Márcia Guimarães de Mello Alves sobre o artigo "A promoção da Saúde e a Prevenção integrada dos Fatores de Risco para Doenças Cardiovasculares". O primeiro se refere à visão da promoção da saúde ainda centrada em modificações no estilo de vida, em detrimento do reconhecimento de que os determinantes sociais estruturam os outros determinantes da saúde, entre eles os comportamentos individuais. O segundo, diz respeito à efetividade das ações em nível comunitário e da Estratégia de Saúde da Família, já que os conceitos de comunidade e de família, como objetos da Atenção à Saúde, não são bem definidos.

Quanto ao primeiro ponto, a reorganização dos serviços de saúde, o acesso à informação e educação em saúde e o desenvolvimento de ha- 
bilidades para uma vida saudável; se inserem nos campos da promoção da saúde ${ }^{1}$, e parecem ser o foco dos programas de base comunitária descritos no artigo. Embora os comportamentos sejam frequentemente entendidos como uma responsabilidade dos indivíduos, sabe-se que eles são fortemente influenciados por determinantes sociais e, por isso mesmo, podem e devem ser alvos de intervenção por meio de medidas universais, destinadas a toda população, compreendendo o acesso à alimentação saudável e a práticas desportivas e a regulamentação da publicidade de alimentos, álcool e tabaco, dentre outros fatores de risco.

É desde esta perspectiva, cuja ênfase é dada à promoção da saúde, que se destacam as ações comunitárias como elo entre as políticas de saúde nacionais e os indivíduos, questões estas muito bem trabalhadas pelo estudioso Milton San$\operatorname{tos}^{2}$ quando enfatiza o conceito de território vivo. Ou seja, é na comunidade onde os grupos vivem e produzem suas relações e condições ligadas à subsistência, salientando-se o saber preexistente e a cultura dos indivíduos, suas concepções sobre saúde e doença, família e sociedade ${ }^{3}$.

Nesta perspectiva, destaca-se neste momento a importância do segundo ponto enfocado, que tange à precariedade da leitura do conceito de comunidade e de família nos serviços de Atenção à Saúde, o que segundo Vasconcelos ${ }^{4}$ :

Ao não ter clara a distinção entre o que deve ser abordado no nivel do indivíduo, da família ou dos diferentes grupos comunitários, o termo família perde a especificidade. Isso ocorre porque o eixo que orienta a intervenção familiar são os programas de saúde pública planejados e padronizados nas instâncias hierarquicamente superiores da burocracia do setor saúde. A percepção e a intervenção dos profissionais locais tendem então a ficar restritas [...].

A reorganização dos serviços de saúde, nesse sentido, deve incluir a mudança do "autoritarismo típico da cultura da saúde pública vigente", além da verticalidade das ações, por meio da mudança também de processos, incluindo os de educação em saúde ${ }^{5}$.

A busca pela referência das "pessoas comuns", realmente muito tem a acrescentar a esse processo. A investigação qualitativa dos fatores determinantes da adesão às mudanças de estilo de vida em portadores de doenças crônicas não transmissíveis, joga luz aos subespaços que vão desde o âmbito coletivo até o individual, relacionando esses aspectos aos espaços institucionais e sociais, alvos de intervenções intersetoriais e integrais ${ }^{6}$.
A visão dos atores coaduna com a necessidade de mudanças nas macroestruturas econômicas, sociais e culturais a partir do conceito mais amplo da promoção da saúde; tarefa que obviamente não cabe somente ao setor e às políticas de saúde. O investimento em políticas públicas, ações intersetoriais e a melhoria da distribuição de renda permanecem como desafios na atualidade às mudanças substanciais da situação de saúde.

Para tanto, conforme destacado pelo professor Aloyzio Achutti, há a necessidade de um planejamento estratégico, considerando a saúde como um processo social em permanente transformação. $\mathrm{O}$ que nos remete à necessidade urgente de mudanças também nos processos e nos modos em que os serviços de saúde se relacionam com a população.

É justamente nesta perspectiva que se descreveu no artigo as diferentes experiências no mundo, com o objetivo de contribuir para a reflexão sobre o modo como os serviços abordam a promoção de saúde nas comunidades, neste contexto as limitações encontradas são destacadas pelo seu potencial para a reflexão sobre esses processos.

Muito nos congratula a contribuição do professor Aloyzio sobre as experiências de base comunitária no país, pelas quais muito agradecemos. De fato, a busca de dados em bases virtuais é um avanço para produção científica, mas apresenta ainda claramente limitações em relação ao acesso e seleção do material.

\section{Referências}

1. World Health Organization (WHO). Carta de Ottawa. In: Ministério da Saúde (MS), Fundação Oswaldo Cruz (Fiocruz). Promoção da Saúde: Cartas de Ottawa, Adelaide, Sundsvall e Santa Fé de Bogotá. Brasília: Ministério da Saúde (MS), IEC; 1986. p. 11-18.

2. Santos M, Silveira ML. O Brasil: Território e sociedade no início do século XXI. Editora Record: Rio de Janeiro; 2001.

3. Campos CEA. O desafio da integralidade segundo as perspectivas da vigilância da saúde e da saúde da família. Cien Saude Colet 2003; 8(2):569-584.

4. Vasconcelos EM. Educação popular e a atenção à saúde da família. São Paulo: Hucitec; 1999.

5. Vasconcelos EM. Educação Popular: de uma Prática Alternativa a uma Estratégia de Gestão Participativa das Políticas de Saúde. Physis 2004; 14(1):67-83.

6. Ribeiro AG, Cotta RMM, Ribeiro SMR, Dias CGC, Araújo RMA. Representações sociais de mulheres portadoras de hipertensão arterial sobre sua enfermidade: desatando os nós da lacuna da adesão ao tratamento na agenda da Saúde da Família. Physis 2011; 21(1):87-112. 